\title{
Cancer- A disease we should care about
}

\author{
Shah Sumaya Jan ${ }^{1}$, Sheikh Mohd Saleem ${ }^{2}$ \\ ${ }^{1}$ Shah Sumaya Jan, Department of Anatomy, Government Medical College, Srinagar, JK, India. ${ }^{2}$ Sheikh Mohd Saleem, \\ Department of Community Medicine, Government Medical College, Srinagar, JK, India.
}

Corresponding Author: Dr. Sheikh Mohd Saleem, Department of Community Medicine, Government Medical College, Srinagar, JK, India. Email: saleem.900@gmail.com

\begin{abstract}
Cancer is primarily an illness of aging. It is being postulated that the Cancer cells use stop inhibitors to cover the body destructive mechanisms and seem to be healthy cells before such destructive mechanisms to flee destruction. Researchers have created artificial promoters that contain DNA sequences which initiate organic phenomenon solely in cancerous cells. A few individuals inherit faulty genes from their ancestors that place them at a higher risk of developing diseases like cancer.
\end{abstract}

Keywords: Cancers, Human Genome, Mutations.

\section{Introduction}

Cancer is primarily an illness of aging which is caused by genomic instability, and various therapies are widely thought to be having a potential effect in combating cancers of various origin [1]. Anyone inquisitive about aging ought to be equally inquisitive about cancer analysis, because the two are much closely coupled, and to have longer life spans, one needs to find all answers about cancers and its pathogenesis. Approaches like interference of check point inhibitors are promising in today's era [2]. It is being postulated that the Cancer cells use stop inhibitors to cover the body destructive mechanisms and seem to be healthy cells before such destructive mechanisms to flee destruction [3].

Unfortunately, despite some successes in finding a cure for cancers, various therapies have remained restricted to tumor-specific antigens - substances that alert the system to the presence of a specific variety of cancer. Another drawback of cancer treatment is that the toxicity of bound therapies, which may do a lot of damage to the human body. Because cancers are all genomically distinctive, this presents an enormous drawback for ancient one-size-fits-all approaches, and, in some cases, solely $30 \%$ to $40 \%$ of patients give a better response to a treatment [2]. In today's world, there's a desire to develop a lot of specific and localized immunotherapies rather than treating the body

\footnotetext{
Manuscript received: $8^{\text {th }}$ April 2018

Reviewed: $18^{\text {th }}$ April 2018

Author Corrected: $25^{\text {th }}$ April 2018

Accepted for Publication: $30^{\text {th }}$ April 2018
}

systemically. There should be a conjointly inquisitive approach of single as well as multiple immunotherapies in a single package which will stimulate the body systems in many ways just in case cancer adapts to the treatment provided. Scientists have already worked and created a factor circuit which is encoded in DNA that helps in finding out cancerous and noncancerous cells [4]. This circuit is also costumed to retort to totally different types of tumors and uses identical principle that and gates in natural philosophy use. These biological AND gates solely activate the circuit once such inputs signals are detected.

The cancerous cell lines are genomically totally undistinguished from the traditional healthy cells of the body and have a unique organic pattern. Researchers have created artificial promoters, that contain DNA sequences which initiate organic phenomenon solely in cancerous cells [5]. This custom circuit is delivered to native cells within the affected region of the body. The artificial promoters then bind to the focus on proteins specifically in neoplasm cells, inflicting the promoters to activate. The DNA circuit itself solely switches on those cancer promoter's areas and activate them. All this suggests that the circuit will specifically target the tumor with higher accuracy than existing therapies [5].

When the circuit is activated, it secretes proteins that attract the cells of the system and directs them to attack the neoplasm cells. This includes surface $\mathrm{T}$ cell 


\section{Original Research Article}

engagers, that direct the $\mathrm{T}$ Cells to destroy the cancer cells. To boot, the circuit expresses a stop matter that removes the barrier to $\mathrm{T}$ cell activity, permitting it to identify the cancer cells and kill them [5].

Lastly, the circuit might be simply reborn to focus on other forms of cancer cells by changing the specific inputs to trigger them. A few individuals inherit faulty genes from their ancestors that place them at a higher risk of developing diseases like cancer. In some people, a number of genes of a specific DNA get amended and lose their specific functions which they are intended to do in normal situations.

This amendment is called mutations. The causes of mutation square measure natural processes in our cells or, sometimes, the cause can be external factors, like tobacco smoking, radiation, ultraviolet rays from the sun, some food substances, chemicals in the environment, and similar different factors.

Mutations in genes happen throughout our lives for higher adaptation. Usually, the cells of human body repair mutation of genes on their own and If the insult is incredibly dangerous or harmful, then they undergo apoptosis or self-destruction as the body system signals them as abnormal cells. Sometimes, mutations in some vital genes of the cells may cause them to behave abnormally. In such circumstances, cells do not understand the directions of genes and start to multiply out indefinitely. The cells are unable to repair themselves and continuously multiply at a higher rate than normal and cause cancer. So, the fault in an exceedingly DNA is accountable for cancerous activity in our body.

Our daily routine, that has activities right from what we have a tendency to eat throughout breakfast to at what time we have a tendency to move to the bed, might facilitate verify however our DNA behaves in preventing or developing cancer in our body. People will get cancer although they are doing all the correct or healthy things throughout their life. Cancer will strike anybody at any time, however living a healthy life will minimize our risk of developing cancer.

\section{Conclusion}

The immunity of a person works in a co-ordinated fashion since conception and protects a human being from various treats from the environment. The mutation in human genes are responsible for cancers and living a healthy life will minimize our risk of developing cancer.

\section{Funding: Nil, Conflict of interest: None Permission of IRB: Yes}

\section{References}

1. Firdous Hussain NS. Role of ATM IVS10-6T $\rightarrow G$ Polymorphism in Breast Cancer; A Case-control Study in High-risk Kashmiri Population. J Carcinog Mutagen [Internet]. 2014; 5(2):1-5.

2. Swart M, Verbrugge I, Beltman JB. Combination Approaches with Immune-Checkpoint Blockade in Cancer Therapy. Front Oncol [Internet]. 2016; 6 (November).

3. Nicholson LB. The immune system. Essays Biochem [Internet]. 2016;60(3):275-301.

4. "Synthetic gene circuit" may improve effectiveness of cancer immunotherapy [Internet]. [cited 2018 Feb 20]. Available from: https://www.medicalnewstoday. com / articles/319804.php\

5. Chen S, Sun H, Miao K, Deng CX. CRISPR-Cas 9 : from Genome Editing to Cancer Research. Int J Biol Sci 2016; 12(12):1427-1436. doi: 10.7150/ ijbs. 17421. Available fromhttp://www.ijbs.com/v12p1427.htm

\section{How to cite this article?}

Shah Sumaya Jan, Sheikh Mohd Saleem. Cancer- A disease we should care about. Int J Med Res Rev 2018;6(04):235236. doi:10.17511/ijmrr. 2018.i04.06. 